\title{
Magnoflorine from Coptidis Rhizoma Protects High Density Lipoprotein during Oxidant Stress
}

\author{
Tran Manh Hung, ${ }^{a}$ Jong Pill Lee, ${ }^{d}$ Byung Sun Min,,${ }^{b}$ Jae Sue Chor,${ }^{c}$ MinKyun NA,${ }^{a}$ XinFeng Zhang, ${ }^{a}$ \\ Tran Minh NGOC, ${ }^{a}$ IkSoo LeE, ${ }^{a}$ and KiHwan BAE*,a \\ ${ }^{a}$ College of Pharmacy, Chungnam National University; Daejeon 305-764, Korea: ${ }^{b}$ College of Pharmacy, Catholic \\ University of Daegu; Gyeongsan 712-702, Korea: ' ${ }^{c}$ Faculty of Food Science and Biotechnology, Pukyong National \\ University; Busan 608-737, Korea: and ${ }^{d}$ Korea Food and Drug Administration; Seoul 122-704, Korea. \\ Received January 8, 2007; accepted March 6, 2007
}

The objective of the present study was to investigate the beneficial properties of magnoflorine, an alkaloid isolated from Coptidis Rhizoma, on protecting human high density lipoprotein (HDL) against lipid peroxidation. Magnoflorine exerts an inhibitory effect against $\mathrm{Cu}^{2+}$-induced lipid peroxidation of $\mathrm{HDL}$, as showed by prolongation of lag time from 62 to $123 \mathrm{~min}$ at the concentration of $3.0 \mu \mathrm{M}$. It also inhibits the generation of thiobarbituric acid reactive substances (TBARS) in the dose-dependent maners with $\mathrm{IC}_{50}$ values of $2.3 \pm 0.2 \mu_{\mathrm{M}}$ and $6.2 \pm 0.5 \mu$ m since HDL oxidation mediated by either catalytic $\mathrm{Cu}^{2+}$ or thermo-labile radical initiator (AAPH), respectively. Separately, $\mathrm{Cu}^{2+}$ oxidized $\mathrm{HDL}$ lost the antioxidant action but the inclusion of magnoflorine/ $\mathrm{Cu}^{2+} \mathrm{oxi}^{-}$ dized HDL can protect LDL oxidation according to increasing magnoflorine concentration. The results suggest that magnoflorine may have a role to play in preventing the HDL oxidation.

Key words Coptidis Rhizoma; magnoflorine; cardiovascular disease; high density lipoprotein; antioxidant

Blood levels of high-density lipoprotein (HDL) are inversely associated with risk for coronary heart disease, ${ }^{1)}$ the most common cause of death. Among the potential mechanisms by which HDL may exert its cardio-protective effect, much attention has recently focused upon its antioxidant function which protects low-density lipoprotein (LDL) from oxidative (i.e., atherogenic) modification. ${ }^{2,3)}$ Numerous prospective cohort studies have demonstrated the protective nature of an elevated level of HDL, and the high risk associated with low levels of this class of lipoprotein. ${ }^{4,5}$ The decrease in atherosclerosis associated with increased HDL levels in human apolipoprotein A-I (apoAI) transgenic animals further illustrates the protective nature of HDL. ${ }^{6-8)} \mathrm{HDL}$ is susceptible to oxidation by a variety of pro-oxidants. ${ }^{9)}$ During incubation with redox-active copper ions $\left(\mathrm{Cu}^{2+}\right), \mathrm{HDL}$ is found to undergo extensive lipid oxidation as indicated by a loss in polyunsaturated fatty acyl content and concurrent accumulation of lipid epoxides, lyso-phosphatidylcholine, and cholesterol oxidation products; thiobarbituric acid-reactive substances, a marker of lipid oxidation, similarly increase in HDL incubated with $\mathrm{Cu}^{2+} \cdot{ }^{10,11)}$ In general, oxidation of HDL is found to result in a loss of cardio-protective properties. For example, the antioxidant ability of HDL to protect LDL from atherogenic modification is lost upon $\mathrm{Cu}^{2+}$-mediated oxidation of HDL. ${ }^{12,13)}$

As a part of our screening program to find antioxidant compounds from natural sources, we have attempted to determine the human density lipoproteins oxidation inhibitory constituents of medicinal plants in Korea. Coptidis Rhizoma (root of Coptis chinensis FRANCH, Ranunculaceae) has been used to treat diabetes mellitus for more than 1000 years in the history of Chinese medicinal remedy. It has long been used for treating gastroenteritis, diarrhea, anti-tumor, and antimicrobial. ${ }^{14-17)}$ Coptidis Rhizoma is currently used for several skin diseases including acne, neurodermatitis, skin ulcers, ${ }^{18)}$ and dermatological indications. ${ }^{19)}$ Moreover, Coptidis Rhizoma is prescribed as a crude drug in folk medicines, such as Oren-gedoku-to and San'o-shashinto, for several vascular disorders. It was useful as an alternative therapy for hypercholesterolemia, effective in preventing hypercholesterolemic atherosclerosis and lowering the relative risk of coronary artery disease through decreases in lipid peroxidation and cholesterol levels. ${ }^{20}$ The alkaloids present in Coptidis Rhizoma (berberine, coptisine, jateorrhizine and palmatine...) were considered to be its active constituents. ${ }^{21,22)}$ Among them, magnoflorine is a quarternary alkaloid with the isoquinoline skeleton. Magnoflorine was showed to suppress the induction phase of the cellular immune response, ${ }^{23)}$ and assigned as noncytotoxic to various human cancer cell lines. ${ }^{24)}$ The antioxidant activity of magnoflorine was investigated with respect to its structural feature and physico-chemical properties to inhibit free radical, peroxidation of dioleoyl phosphatidylcholine, and liposomes initiated by thermal degradation of the azoinitiator (AAPH) ${ }^{25)}$ However, no studies have been specifically investigated the ability of this antioxidant to protect human density lipoprotein from oxidation. In this study, we examined the susceptibility of HDL to in vitro $\mathrm{Cu}^{2+}$ and $\mathrm{AAPH}$ induced lipid peroxidation in the presence of magnoflorine. Also, the study of magnoflorine/ $\mathrm{Cu}^{2+}$ oxidized HDL in preventing LDL oxidation was used to investigate whether the inclusion protects LDL from oxidative modification.

\section{MATERIALS AND METHODS}

Plant Material The root of Coptis chinensis FRANCH (Coptidis Rhizoma) was purchased from a local market in Daejeon, Korea in June 2006, and was identified by Prof. KiHwan Bae. A voucher specimen (CNU 1286) was deposited in the herbarium of the College of Pharmacy, Chungnam University.

Extraction and Isolation Dried plant material $(6.0 \mathrm{~kg})$ was extracted with hot $\mathrm{MeOH}$, refluxed for $3 \mathrm{~h}(3 \mathrm{l} \times 3$ times $)$ to yield a methanolic extract $(320 \mathrm{~g})$. The extract was sus- 
pended in $\mathrm{H}_{2} \mathrm{O}$ and then partitioned with $\mathrm{CH}_{2} \mathrm{Cl}_{2}$ and EtOAc. The aqueous layer was subjected to Diaion column chromatography and eluted with a stepwise gradient of $\mathrm{H}_{2} \mathrm{O}$ and $\mathrm{MeOH}\left(\mathrm{H}_{2} \mathrm{O} \rightarrow 40 \% \mathrm{MeOH}, 40 \rightarrow 60 \% \mathrm{MeOH}\right.$, and $60 \rightarrow 100 \% \mathrm{MeOH})$ to give three subfractions (F1-F3). The subfraction F2 (35 g) was continually separated by MCI gel CHP20P column chromatography using $\mathrm{H}_{2} \mathrm{O}$ and $\mathrm{MeOH}$ gradient $\left(\mathrm{H}_{2} \mathrm{O} \rightarrow 30 \% \mathrm{MeOH}, 35 \rightarrow 80 \% \mathrm{MeOH}\right)$ to give $\mathrm{F} 2.1$ $(20 \mathrm{~g})$ and F2.2 (6g). F2.2 was re-subjected to MCI gel CHP20 column chromatography using 2\% AcOH-MeOH $(1: 1)$, magnoflorine $(15.5 \mathrm{mg})$ was obtained by crystallization in $\mathrm{MeOH}$ from the collected subfraction F2.2.3.

Magnoflorine: Colorless crystal, mp $210-212{ }^{\circ} \mathrm{C}$; IR $v_{\max }$ (KBr) $3400(\mathrm{OH}), 1645,1640$ (aromatic ring) cm ${ }^{-1}$; UV, $\lambda_{\max }^{\mathrm{MeOH}} 230,280,323 \mathrm{~nm}$; FAB-MS $m / z \quad 343[\mathrm{M}+\mathrm{H}]^{+}$, $\mathrm{C}_{20} \mathrm{H}_{24} \mathrm{NO}_{4} \cdot{ }^{1} \mathrm{H}$ - and ${ }^{13} \mathrm{C}$-NMR spectral data were in accordance with published paper. ${ }^{23,24)}$

HDL and LDL Preparation Blood from healthy normolipemic donors was obtained by venipuncture and collected in EDTA-containing vacutainer tubes. LDL was prepared from plasma by sequential flotation ultracentrifugation as described previously. ${ }^{26}$ To isolate HDL, plasma was prepared by centrifugation at $3000 \mathrm{rpm}$ for $10 \mathrm{~min}$ and thereafter used for the preparation of plasma lipoproteins. HDL was isolated from plasma by ultracentrifugation for $1: 30 \mathrm{~h}$ with a vertical rotor. ${ }^{27)}$ After dialysis at $4{ }^{\circ} \mathrm{C}$ for $24 \mathrm{~h}$ against $10 \mathrm{~mm}$ phosphate-buffered saline (PBS) $\mathrm{pH} 7.4$, HDL protein concentration $(\mu \mathrm{g}$ protein $/ \mathrm{ml})$ was determined as described by Lowry et al. ${ }^{28)}$

$\mathbf{C u}^{2+}$ Mediated HDL Oxidation The oxidation of HDL was assessed by the formation of conjugated dienes determined as the change in UV absorbance at $232 \mathrm{~nm}$. Briefly, HDL $(200 \mu \mathrm{g} / \mathrm{ml})$ in PBS ( $\mathrm{pH} 7.4)$ was pre-incubated with either the absence (control) or presence of magnoflorine (various concentrations), and then $\mathrm{Cu}^{2+}(5 \mu \mathrm{M})$ was added to initiate the oxidation at $37^{\circ} \mathrm{C}$. Absorbance at $232 \mathrm{~nm}$ was continuously monitored at $10 \mathrm{~min}$ intervals for $5 \mathrm{~h}$ at $37^{\circ} \mathrm{C}$ using a spectrophotometer (Shimadzu UV-1240, Tokyo, Japan). The lag time was measured as the intercept between the baseline and the tangent of the absorbance curve during the propagation phase. ${ }^{29,30}$ ) The oxidation of HDL to malondialdehyde (MDA) was measured using the thiobarbituric acid reactive substances (TBARS) assay. Briefly, HDL $(200 \mu \mathrm{g} / \mathrm{ml})$ in PBS ( $\mathrm{pH} 7.4)$ was pre-incubated with magnoflorine, and then $\mathrm{Cu}^{2+}$ was added to initiate the oxidation. The reaction mixture was incubated at $37^{\circ} \mathrm{C}$ for $2 \mathrm{~h}$ and the reaction was terminated by adding 20\% trichloroacetic acid (TCA) and $1 \%$ thiobarbituric acid (TBA). After boiling at $95^{\circ} \mathrm{C}$ for $15 \mathrm{~min}$, the mixture was centrifuged at $10000 \mathrm{rpm}$ for $10 \mathrm{~min}$. The absorbance of supernatant was measured at $532 \mathrm{~nm}$.

Peroxyl Radicals Mediated HDL Oxidation Oxidation of HDL by peroxyl radicals was performed by incubation of the HDL $(200 \mu \mathrm{g} / \mathrm{ml})$ at $37^{\circ} \mathrm{C}$ in PBS (pH 7.4) with one of the thermo-labile radical initiator (AAPH) for $2 \mathrm{~h}$. AAPH $(10 \mathrm{~mm})$ served as a source of hydrophilic peroxyl radicals. ${ }^{31)}$ At the end of the incubation, samples were also assessed by measuring accumulation of lipid aldehydes (TBARS) as described above.

Effect of Magnoflorine/ $\mathrm{Cu}^{2+}$ Oxidized HDL in LDL Oxidation HDL $(1000 \mu \mathrm{g} / \mathrm{ml})$ was pre-incubated with $\mathrm{Cu}^{2+}(5 \mu \mathrm{M})$ for $1 \mathrm{~h}$ in the presence or absence of mag- noflorine $(0-10 \mu \mathrm{M})$ in PBS buffer $(10 \mathrm{~mm}, \mathrm{pH} 7.4)$ at $4{ }^{\circ} \mathrm{C}$. Native HDL or oxidized HDL $(0.1 \mathrm{mg} / \mathrm{ml})$ was incubated with $\mathrm{LDL}(0.1 \mathrm{mg} / \mathrm{ml})$ in the presence of $\mathrm{Cu}^{2+}(0.5 \mu \mathrm{M})$ at $37^{\circ} \mathrm{C}$, and $3 \mathrm{~h}$ later, the lipid oxidation was assessed by the measurement of peroxide values as described previously. ${ }^{32)}$ The inhibition of LDL oxidation by HDL under these conditions was calculated according to the formular:

$$
\begin{aligned}
& \text { inhibition of LDL oxidation (\%) } \\
& \quad=\left[\left(A_{\mathrm{HDL}}+A_{\mathrm{LDL}}\right)-A_{\mathrm{HDL}+\mathrm{LDL}}\right] \times 100 /\left(A_{\mathrm{HDL}}+A_{\mathrm{LDL}}\right)
\end{aligned}
$$

Where $\left(A_{\mathrm{HDL}}+A_{\mathrm{LDL}}\right)$ is the sum of the absorbances observed for HDL and LDL incubated separately with $\mathrm{Cu}^{2+}$ for $3 \mathrm{~h}$, and $A_{\mathrm{HDL}+\mathrm{LDL}}$ is the absorbance observed during co-incubation of LDL with HDL and $\mathrm{Cu}^{2+}$ for $3 \mathrm{~h}$.

Statistical Analysis The results are expressed as mean values \pm S.D. Statistical analysis was performed using oneway ANOVA. A $p<0.05$ was considered statistically significant.

\section{RESULTS AND DISCUSSION}

Numerous studies have found that HDL is readily modified using a variety of oxidants in vitro. These include transition metal ions, aqueous peroxyl and hydroxyl radicals, aldehydes, peroxidase-generated tyrosyl radical, cigarette smoke, lipoxygenase, hypochlorous acid, cultured endothelial cell, and macrophages. ${ }^{9,33)}$ As part of an ongoing study to search for antioxidants from traditional medicine plants, we have focused on the water layer of Coptidis Rhizoma with the expectation that we could find out more anti-lipid peroxidation agents. Repeated column chromatography led to the isolation of a colorless crystal compound. This compound was identified as magnoflorine by analyses of MS, NMR data, and comparison with those in the literature (Fig. 1). ${ }^{23)}$

Since the formation of conjugated dienes represents the initiate phase of HDL oxidation, the extent of lag time is indicated as oxidation resistant capacity of HDL. As shown in Fig. 2, spectrophotometric analysis of $\mathrm{Cu}^{2+}$-induce HDL oxidation based on the conjugated dienes formation due to the unsaturated lipids is presented. When the HDL was incubated with $\mathrm{Cu}^{2+}$ alone, the lag time was $62 \mathrm{~min}$, whereas, in the presence of magnoflorine $(3.0 \mu \mathrm{M})$, the lag phase was retarded to $123 \mathrm{~min}$. In this experiment, the lag phases of vita$\min \mathrm{C}(3.0 \mu \mathrm{M})$ and vitamin $\mathrm{E}(3.0 \mu \mathrm{M})$ retarded to 97 and $145 \mathrm{~min}$, respectively (Table 1 ).

The oxidation of HDL initiated by $\mathrm{Cu}^{2+}$ and thermo-labile radical initiator AAPH was also measured by the formation of malondialdehyde (MDA) using the TBARS assay. As shown in Table 1, the compound tested remarkably reduced the formation of TBARS, comparable to the results of conjugated diene formation. Magnoflorine exhibited significant

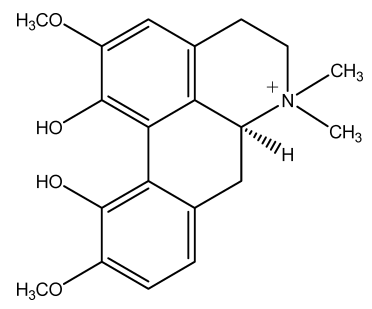

Fig. 1. Magnoflorine Structure 


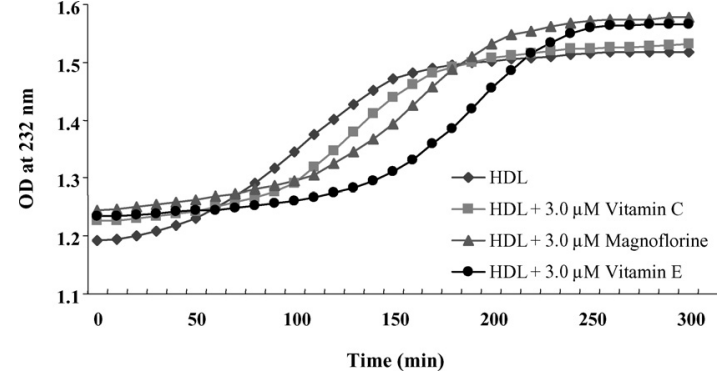

Fig. 2. Conjugated Diene Effect of Magnoflorine on the $\mathrm{Cu}^{2+}$-Mediated HDL Oxidation

HDL $(200 \mu \mathrm{g} / \mathrm{ml})$ in PBS (pH 7.4) was pre-incubated with vitamin C $(3.0 \mu \mathrm{M})$, vita$\min \mathrm{E}(3.0 \mu \mathrm{M})$ or magnoflorine $(3.0 \mu \mathrm{M})$, and then $\mathrm{Cu}^{2+}(5 \mu \mathrm{M})$ was added to initiate the oxidation at $37^{\circ} \mathrm{C}$. Conjugated diene was measured by determined the absorbance at $232 \mathrm{~nm}$ continuously at $10 \mathrm{~min}$ intervals for $5 \mathrm{~h}$ at $37^{\circ} \mathrm{C}$.

Table 1. Effect of Magnoflorine on the Oxidation of HDL by TBARS Method

\begin{tabular}{lccc}
\hline \hline & & \multicolumn{2}{c}{$\operatorname{TBARS}_{\text {Compound }} \mathrm{IC}_{50}(\mu \mathrm{M})^{b)}$} \\
& Lag time $(\mathrm{min})^{a)}$ & $\mathrm{Cu}^{2+}$-mediated & AAPH-mediated \\
\cline { 3 - 4 } & & $2.3 \pm 0.2^{*, \dagger}$ & $6.2 \pm 0.5^{*, \dagger}$ \\
Magnoflorine & 123 & $10.5 \pm 0.8$ & $18.7 \pm 1.5$ \\
Vitamin C $^{c)}$ & 97 & $1.8 \pm 0.2$ & $4.4 \pm 0.5$ \\
Vitamin $^{c)}$ & 145 & & \\
\hline
\end{tabular}

a) The lag time of blank was estimated to be $52 \mathrm{~min}, b$ ) the values represent mean \pm S.D. of triplicate experiments, $c$ ) compound used as positive control; $* p<0.05$ vs. vitamin $\mathrm{C}, \uparrow p<0.05$ vs. vitamin $\mathrm{E}$.

inhibitory activity against $\mathrm{Cu}^{2+}$ - and AAPH mediated HDL oxidation in the dose dependent manners entirely with $\mathrm{IC}_{50}$ values of $2.3 \pm 0.2$ and $6.2 \pm 0.5 \mu \mathrm{M}$, respectively. Vitamin $\mathrm{C}$ showed inhibitory activity with $\mathrm{IC}_{50}$ values of $10.5 \pm 0.8 \mu \mathrm{M}$ and $18.7 \pm 1.5 \mu \mathrm{M}$, meanwhile, vitamin $\mathrm{E}$ showed inhibitory activity with $\mathrm{IC}_{50}$ values of $1.8 \pm 0.2 \mu \mathrm{M}$ and $4.4 \pm 0.5 \mu \mathrm{M}$, under $\mathrm{Cu}^{2+}$ and AAPH mediated oxidation.

The effective action of magnoflorine on the ability of HDL to protect $\mathrm{LDL}$ from $\mathrm{Cu}^{2+}(0.5 \mu \mathrm{M})$-mediated oxidation was evaluated by the measurement of the peroxide value. As showed in Fig. 3, the oxidized HDL (HDL-0), which was prepared from exposure of HDL to $\mathrm{Cu}^{2+}(5 \mu \mathrm{M})$ in the absence of magnoflorine, expressed a slight protection (28.5\%), while native HDL was highly effective $(68.8 \%)$ in protecting LDL from the oxidation. The inclusion of magnoflorine $/ \mathrm{Cu}^{2+}$ oxidized HDL preparations (HDL-1.0, -2.0, -5.0, -10.0) decreased lipid oxidation of LDL progressively with increasing concentration of magnoflorine $(1.0,2.0,5.0,10.0 \mu \mathrm{M})$. It is suggested that the ability of magnoflorine/ $\mathrm{Cu}^{2+}$ oxidized HDL in preventing LDL oxidation maybe related to the oxidation state of HDL after pre-incubation.

Oxidative modifications that would affect the capability of HDL to protect against atherosclerosis are of considerable importance and interest. The exact beneficial effects of HDL in vivo remain unknown. HDL may also be protective by inhibiting the oxidation of LDL, and by neutralizing the atherogenic effects of oxidized LDL.9) However, certain forms of oxidized HDL may actually enhance protection by stimulating the delivery of intracellular cholesterol to cell surface sites where it becomes available for removal by other (non-oxidized) HDL particles. ${ }^{10)}$ Lipid oxidation in HDL is promoted by a variety of factors. In this study, we used $\mathrm{Cu}^{2+}$,

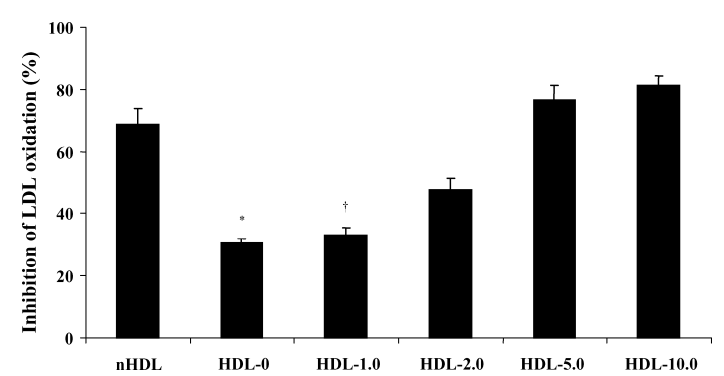

Fig. 3. Effect of Magnoflorine/ $\mathrm{Cu}^{2+}$ Oxidized HDL in LDL Oxidation

After $3 \mathrm{~h}$ incubation, an aliquot was taken for the assay of lipid peroxidation, based on the measurement of the peroxide values. nHDL is native HDL. HDL-0, $-1.0,-2.0$, -5.0 , and -10.0 indicate the HDL oxidized with $\mathrm{Cu}^{2+}$ in the presence of magnoflorine at $0,1.0,2.0,5.0$, and $10.0 \mu \mathrm{M}$, respectively. $* p<0.05 v s$. nHDL, $\dagger p<0.05 v s$. HDL-0.

a metal ion-independent oxidant, and AAPH, a hydrophilic peroxyl radicals as the activation sources. That is consistent with those of numerous other investigators who reported that lipids in HDL are highly susceptible to oxidation during incubation with $\mathrm{Cu}^{2+}$ and AAPH. ${ }^{13,27,31)}$ Although there have been a number of reports on the designing and development of synthetic lipid peroxidation inhibitors, that were necessary for those other studies, which have been reported the HDL oxidation inhibitors derived from medicinal plants. ${ }^{27,30)}$ Specially, boldine, an antioxidant alkaloid isolated from Peumus boldus, which has similar chemical structure with magnoflorine, has been well established to have free radical scavenger, prevents the oxidation of LDL in vitro and in vivo. ${ }^{34)}$

Our results clearly demonstrate that magnoflorine significantly inhibits lipid oxidation in HDL exposed to a metal ion-independent form and peroxyl radicals mediated of oxidant stress. Magnoflorine, even at low concentration $(3.0 \mu \mathrm{M})$ could exert a protective effect against $\mathrm{Cu}^{2+}$ induced lipid peroxidation of HDL, as showed by decrease the lag time of conjugated diene process. Interestingly, magnoflorine is more effective than vitamin $\mathrm{C}$ but less than vitamin $\mathrm{E}$ by retarding lag phase (Fig. 2), and further evidence by TBARS method (Table 1). Since magnoflorine was a more effective antioxidant in the metal-dependent pro-oxidant system $(2.3 \mu \mathrm{M})$ compared to the peroxyl radical system $(6.2 \mu \mathrm{M})$, metal ion chelating properties may underlie magnoflorin's apparent antioxidant effects towards HDL oxidation in vitro. In addition, HDL has been recognized to have antioxidant action to protect LDL from oxidative modification, this might be supported by present finding that the oxidized HDL, prepared from the exposure of HDL to $\mathrm{Cu}^{2+}$ in combination with magnoflorine, exerted an antioxidant action against LDL oxidation.

The antioxidant effect of magnoflorine is due to its chemical structure. Magnoflorine is an alkaloid bearing two free phenolic groups. The presence of aromatic-OH group may be responsible for their antioxidant efficiency, similarly to phenolic antioxidants, ${ }^{35)}$ via chain-breaking mechanism by donation of phenolic hydrogen. Moreover, magnoflorine showed a lower value of $\mathrm{O}-\mathrm{H}$ bond dissociation energy, and highest occupied molecular orbital surroundings of the reaction center, which have been identified as important requisites for both chelating and radical scavenging activity and explaining the higher antioxidant efficiency of the former compound. ${ }^{25)}$

The hypothesis that Coptidis Rhizoma would be useful as an alternative therapy for hypercholesterolemia, thus, mag- 
noflorine and some other constituents are able to play an important roll on reducing oxidative stress, prevent the development and progression of athesclerotic disease. In summary, our results demonstrate that magnoflorine could inhibit lipid oxidation in HDL but the cardioprotective ability of this lipoprotein fraction in combination with magnoflorine to prevent atherogenic modification of LDL should be more preserved.

Acknowledgements This work was supported by a grant funded from the Korean Food and Drug Administration (2007).

\section{REFERENCES}

1) National Heart, Lung, and Blood Institute, Third Report of the National Cholesterol Education Program (NCEP) Expert Panel on Detection, Evaluation, and Treatment of High Blood Cholesterol in Adults (Adult Treatment Panel III): Final Report, National Institutes of Health (2002).

2) Nofer J. R., Kehrel B., Fobker M., Levkau B., Assmann G., von Eckardstein A., Atherosclerosis, 161, 1-16 (2002).

3) Assmann G., Nofer J. R., Annu. Rev. Med., 54, $321-341$ (2003).

4) Stampfer M. J., Sacks M. D., Salvini S., Willett S. C., Hennekens C. H., New Engl. J. Med., 325, 373-381 (1991).

5) Rubins H. B., Robins S. J., Iwane M. K., Boden W. E., Elam M. B., Fye C. L., Gordon D. J., Schaefer E. J., Schectman G., Wittes J. T., Am. J. Cardiol., 71, 45-52 (1993).

6) Rubin E. M., Krauss R. M., Spangler E. A., Verstuyft J. G., Clift S. M., Nature (London), 353, 265-267 (1991).

7) Paszty C., Maeda N., Verstuyft J., Rubin E. M., J. Clin. Invest., 94, 899-903 (1994).

8) Plump A. S., Scott C. J., Breslow J. L., Proc. Natl. Acad. Sci. U.S.A., 91, 9607-9611 (1994).

9) Francis G. A., Biochim. Biophys. Acta, 1483, 217-235 (2000).

10) Nagano Y., Arai H., Kita T., Proc. Natl. Acad. Sci. U.S.A., 88, 64576461 (1991).

11) Parthasarathy S., Barnett J., Fong L. G., Biochim. Biophys. Acta, 1044, $275-283$ (1990).

12) Jaouad L., Milochevitch C., Khalil A., Free Radic. Res., 37, 77-83 (2003).

13) Hillstrom R. J., Yacapin-Ammons A. K., Lynch S. M., J. Nutr., 133
$3047-3051$ (2003).

14) Iizuka N., Miyamoto K., Hazama S., Yoshino S., Yoshimura K., Okita K., Fukumoto T., Yamamoto S., Tangoku A., Oka M., Cancer Lett., 158, 35-41 (2000).

15) Lee D. U., Kang Y. J., Park M. K., Lee Y. S., Seo H. G., Kim T. S., Kim C. H., Chang K. C., Life Sci., 73, 1401-1412 (2003).

16) Hwang B. Y., Roberts S. K., Chadwick L. R., Wu C. D., Kinghorn A D., Planta Med., 69, 623-627 (2003).

17) Yu H. H., Kim K. J., Cha J. D., Kim H. K., Lee Y. E., Choi N. Y., You Y. O., J. Med. Food, 8, 454-461 (2005).

18) Higaki S., Nakamura M., Morohashi M., Hasegawa Y., Yamagishi T., J. Dermatol., 23, 871-875 (1996).

19) Nam C., Kim S., Sim Y., Chang I., Skin Pharmacol. Appl. Skin Physiol., 16, 84-90 (2003).

20) Yokozawa T., Ishida A., Cho E. J., Nakagawa T., Phytomedicine, 10 $17-22$ (2003)

21) Otsuka H., Tsukui M., Matsuoka T., Goto M., Fujimura H., Hiramatsu Y., Sawada T., Yakugaku Zasshi, 94, 796-801 (1974).

22) Peng W. H., Haieh M. T., Wu C. R., Jpn. J. Pharmacol., 74, 261-266 (1997).

23) Mori H., Fuchigami M., Inoue N., Nagai H., Koda A., Nishioka I., Planta Med., 60, 445-449 (1994).

24) Min Y. D., Choi S. U., Lee K. R., Arch. Pharm. Res., 29, 627-632 (2006).

25) Račková L., Májeková M., Košt’álová D., Štefek M., Bioorg. Med. Chem., 12, 4709-4715 (2004).

26) Hung T. M., Na M. K., Thuong P. T., Su. D., Sok D. E., Song K. S. Seong Y. H., Bae K., J. Ethnopharmacol., 108, 188-192 (2006).

27) Ferretti G., Bacchetti T., Menanno F., Curatola G., Atherosclerosis, 172, 55-61 (2004)

28) Lowry O. H., Rosebrough N. J., Farr A. L., Randall P. J., J. Biol. Chem., 193, 265-275 (1951).

29) Puhl H., Waeg G., Esterbauer H., Methods Enzymol., 233, 425-441 (1994).

30) Sobal G., Sinzinger H., Biochem. Pharmacol., 70, 1185-1191 (2005).

31) Calla M. S., Lynch S. M., Arch. Biochem. Biophys., 452, 129-137 (2006).

32) Raveh O., Pinchuk I., Schnitzer E., Fainaru M., Schaffer Z., Lichtenberg D., Free Radic. Biol. Med., 29, 131-146 (2000).

33) Steinberg D., J. Biol. Chem., 272, 20963 -20966 (1997).

34) Santanam N., Penumetcha M., Speisky H., Parthasarathy S., Atherosclerosis, 173, 203-210 (2004).

35) Bors W., Heller W., Michel C., Saran M., Methods Enzymol., 186 $343-355$ (1990) 